\title{
Beliren Yetişkinlikte Psikolojik Dayanıklılık ve Affedicilik: Bilişsel Kontrol/Esnekliğin Paralel Çoklu Aracılı̆̆1
}

\author{
DOI: $10.26466 /$ opus.790362
}

*

\author{
Ayşe Sibel Demirtaş * \\ * Doç. Dr., Alanya Alaaddin Keykubat Üniversitesi \\ E-Posta: sibel.demirtas@alanya.edu.tr \\ ORCID: 0009-0001-7793-9583

\section{Öz}

Bu çalışmada, beliren yetişkinlerde affediciliğin yordanmasına yönelik bir model geliştirilmesi amaçlanmıştır. Önerilen hipotez modelde, psikolojik dayanıklılık ve affedicilik arasındaki ilişkide bilişsel kontrollesnekliğin paralel çoklu aracılı̆̆ı test edilmiştir. Araştırma, Akdeniz Bölgesi'ndeki bir devlet üniversitesinde eğitim alan 354 öğrenci üzerinde gerçekleştirilmiştir. Katılımclların 141'i (\%40) Eğitim Fakültesi'nin çeşitli bölümlerinde lisans eğitimi alan öğrencilerden, 213'ü (\% 60) pedagojik formasyon eğitimi alan öğrencilerden oluşmaktadır. Katılımcılarm 142'si (\% 40.1) kadın, 184'ü (\% 52) erkektir. 28 kişi (\%7.9) cinsiyetini belirtmemiştir. Katıllımcıların yaş ortalamaları 22.79'dur (SS: 4.20). Verilerin toplanmasında Ego-Dayanıklllı Ölçeği, Bilişsel Kontrol/Esneklik Ölçeği ve Heartland Affedicilik Ölç̧̆̆i; verilerin analizinde betimsel istatistikler, Pearson korelasyon katsayısı ve aracılı analizleri kullanılmıştır. Elde edilen bulgular, psikolojik dayanıklılık, affedicilik, bilişsel kontrollesneklik değ işkenleri arasında pozitif yönde anlamlı ilişkiler olduğunu ortaya koymuştur. Aracılık etkisi için yapılan analizde ise psikolojik dayanıklilık ile affedicilik arasında bilişsel kontrol/esnekliğin paralel çoklu aracilı̆̆ istatistiksel açıdan anlamlı bulunmuştur. Çalışmanın bulguları ışı̆̆ında, psikolojik dayanıklılı̆̆a sahip bireylerin olumsuz duygu ve düşüncelerini kontrol edebilme, bunları yönetebilme ve alternatif başa çıkma stratejileri oluşturabilme becerisine sahip olduğu, ve bu özellikleri sayesinde daha fazla affedici olduklar söylenebilir.

Anahtar Kelimeler: $\quad$ psikolojik dayanıklılık, affedicilik, bilişsel kontrol, bilişsel esneklik 


\title{
Ego-Resiliency and Forgiveness in Emerging Adults: The Parallel Multiple Mediation of Cognitive Control/Flexibility
}

\begin{abstract}
This study was designed to develop a model for predicting forgiveness in emerging adults. The parallel multiple mediation of cognitive control/flexibility was tested in the relationship between ego-resiliency and forgiveness in the hypothesized model. The study was carried out with 354 students who were recruited from a state university in the Mediterranean Region. Of the 354 participants 141 (40\%) were students who received undergraduate education in various departments of the Faculty of Education, $213(60 \%)$ were students who received pedagogical training. $142(40.1 \%)$ of the participants were female and $184(52 \%)$ were male. 28 participants $(7.9 \%)$ did not declare gender. The mean age of the participants was 22.79 (SD: 4.20). Ego-Resiliency Scale, Cognitive Control/Flexibility Questionnaire, and Heartland Forgiveness Scale were used to collect data. Descriptive statistics, Pearson correlation coefficient, and mediation analysis were used in the study. The findings revealed that there were positive relationships among ego-resiliency, forgiveness and cognitive control/flexibility. In the analysis for the mediating effect, the parallel multiple mediation of cognitive control/flexibility in the relationship between ego-resiliency and forgiveness was found to be statistically significant. In the light of the findings of the study, it can be said that individuals with psychological resilience have the ability to control their negative emotions and thoughts, manage them, and create alternative coping strategies, and thanks to these features, they are more forgiving.
\end{abstract}

Keywords: ego-resiliency, forgiveness, cognitive control, cognitive flexibility 


\section{Giriş}

Pozitif duyguların ve pozitif karakter özelliklerinin gelişimiyle ilgili araştırmalar ve uygulamalar yapan pozitif psikoloji yaklaşımı, kişilerarası durumların pozitif kişilerarası ilişkiler ve içsel olarak yansıması yoluyla çözülmesinden kaynaklanan artan iyi oluşu ve uyumu vurgulamaktadır (Seligman, 2002; Lopez, Snyder, ve Rasmussen, 2002). Bu görüşle uyumlu olarak, alan yazında affetmenin, fiziksel, ruhsal ve sosyal sağlığı etkileyerek hem hataya uğrayan hem de hata yapan kişi için psikolojik olarak faydalı olduğu belirtilmektedir (Worthington, Berry, ve Parrott, 2001).

İnsanlar, doğuştan getirdikleri sosyal doğası nedeniyle, kaçınma ve intikam peşinde olmaya yönelik motivasyonları karşısında diğerleriyle olumlu ilişkiler sürdürmeye yönelik güçlü bir motivasyona sahiptirler (McCollough, 2000). McCollough'a (2000) göre affetme, sosyal yaşamda meydana gelen diğer prososyal değişimler (örn. empati) ile benzerlik göstermektedir. Buna göre, affetmede kişi, başka bir kişinin veya bir ilişkinin iyi oluşuna katkıda bulunacak şekilde hareket eder. Bu araştırmada ele alınan affetme kavramı ise Thompson ve diğerlerinin (2005) yaklaşımına dayanmaktadır. Bu yaklaşımda affetme, algılanan ihlalin, bireyin, ihlal eden, ihlal ve ihlalin yarattığ1 sonuçlara yönelik tepkilerinin negatiften nötr veya pozitife dönüştürüleceği şekilde düzenlenmesi olarak kavramsallaştırılmaktadır. Bu görüşe göre, insanlar affettiğinde, bir ihlalin meydana geldiğini kabul ederler ve daha sonra ihlale yönelik tepkileri artık negatif olmayacak şekilde ihlali yeniden çerçevelemek için gerekli bilişsel, duygusal ve/veya davranışsal çalışmaları yaparlar. $\mathrm{Bu}$, insanlar affettiğinde, ihlali yapan kişiyi ya da ihlali göz ardı ettikleri veya mazur gördükleri anlamına gelmez. Aksine, affetme, insanların önceki varsayımlarını ve ihlalin gerçekliğini; ihlal, ihlali yapan kişi, ihlalin yarattığı sonuçları ve potansiyel olarak kendilerinin, diğer insanların veya dünyanın yeni bir anlayışına sentezlediği diyalektik bir süreçtir (Thompson vd., 2005). Dargın bir kişi affettiğinde, (a) intikam almayı isteme ve (b) ihlali yapan kişi ile temastan kaçınmaya yönelik temel motivasyonları azalır ve ilişkiyi yapılandırmaya yönelik motivasyonları (olumlu bir ilişkiyi sürdürme motivasyonu gibi) geri döner (McCullough, Bellah, Kilpatrick, ve Johnson, 2001). Yapılan araştırmalar affetmenin pek çok olumlu sonuçla ilişkili olduğunu ortaya koymuştur. Örneğin, Bono, McCullough ve Root (2008) tarafından yap1- 
lan boylamsal çalışmada, affetmedeki artışların, yaşamdan daha fazla memnuniyet, daha olumlu ruh hali, daha az olumsuz ruh hali ve daha az fiziksel semptom ile ortaya çıkan psikolojik iyi oluşla ilişkili olduğu gösterilmiştir. Diğer taraftan intikam alma, daha az affetme, hatalı davranış hakkında daha fazla ruminasyon, daha yüksek olumsuz duygulanım ve daha düşük yaşam memnuniyeti ile ilişkilendirilmiştir (McCullough vd., 2001). Bazı araştırmacılar ise affediciliği yordayan özellikleri ortaya çıkarmaya dönük çalışmalar yapmışlardır. Örneğin, Turnage, Hong, Stevenson ve Edwards (2011) benlik saygısının, kendini affetmenin ve başkalarını affetmenin önemli bir yordayıcısı olduğunu; empatinin ise başkalarını affetmenin önemli bir yordayıcısı olduğunu bildirmişlerdir.

Affedicilikle yakından ilişkili diğer önemli bir yapı psikolojik dayanıklılıktır. Block ve Cremen (1996) psikolojik dayanıklılığı, "bireyin sistem dengesini korumak veya geliştirmek için çevresel bağlamın talep özelliklerinin bir fonksiyonu olarak her iki yönde karakteristik bir ego kontrol seviyesini değiştirme kapasitesinin dinamik olması" şeklinde tanımlamışlardır. Bu tanıma göre, psikolojik dayanıklılık, sürekli değişen durumlara, arzulara ve çevresel taleplere esnek bir şekilde uyum sağlama, diğer bir ifadeyle bireyin davranıŞını çeşitli koşullara göre uyarlama kapasitesidir (Block, 2002). Psikolojik dayanıklılık kavramı, benliğin üst düzey bir kişilik bileşenidir ve bu nedenle bir kişilik özelliği veya nispeten istikrarlı bir bilişsel yapı veya şema olarak görülebilir (Philip, Laventure, Beaulieu-Pelletier, ve Lekes, 2011). Klohnen (1996) psikolojik dayanıklılı̆̆ın, yaşamın farklı alanlarında etkili şekilde işlem yapma ile ilişkili olduğunu ortaya koymuştur. Üniversite öğrencileri üzerinde yapılan bir araştırmada, yüksek düzeyde dayanıklılığa sahip katılımcıların daha olumlu düşünceleri sürdürdüğü ve daha yüksek yaşam memnuniyeti ve daha düşük depresyon düzeyleri bildirdiği bulunmuştur (Mak, $\mathrm{Ng}$, ve Wong, 2011). Ayrıca, alan yazın psikolojik dayanıklılık ve affedicilik arasındaki ilişkiye yönelik önemli kanıtlar sunmaktadır. Örneğin, Anderson (2006) ergenler üzerinde yürüttüğü araştırmada psikolojik dayanıklılık, affedicilik ve öfke ifade türleri arasında önemli ilişkiler olduğunu belirtmiştir. Ayrıca, Divvyalakshmi ve Indumathy (2018) psikolojik dayanıklılık, affedicilik ve iyi oluş arasındaki ilişkileri genç yetişkinler üzerinde yürüttükleri araştırmada incelemişler ve anlamlı ilişkiler olduğunu bildirmişlerdir. 
Psikolojik dayanıklılık ve affedicilikle ilişkili diğer önemli bir yapı bilişsel esnekliktir. Bilişsel esnekliğe yönelik önerilen tanımların ortak özelliği “değişen çevresel uyaranlara uyum sağlamak için bilişsel yapıları değiştirme becerisi" şeklindedir (Dennis ve Vander-Wal, 2010, s.242). Martin ve Rubin (1995) bilişsel esnekliği, bir kişinin "(a) herhangi bir durumda, seçenekler ve alternatiflerin mevcut olduğuna ilişkin farkındalığı, (b) esnek olma ve duruma uyum sağlama istekliliği ve (c) esnek olma konusunda öz-yeterliliğe sahip olması" (s. 1) şeklinde kavramsallaştırmaktadırlar. Bilişsel olarak esnek bireyler, ortaya çıkan değişiklikleri tanımlama ve aniden gelişebilecek durumlara hazırlıklı olmak için birden fazla strateji oluşturma yeteneğine sahiptirler (Gurvis ve Calarco, 2007). Gabrys, Tabri, Anisman, ve Matheson'a göre (2018) bilişsel esneklik, duygular üzerinde bilişsel kontrol ile değerlendirme ve başa çıkma esnekliği olmak üzere iki faktörden oluşan bir yapıdır. Gabrys ve diğerlerinin (2018) bilişsel kontrol/esneklik modeline göre, duyguları üzerinde bilişsel kontrol sahibi olduğunu algılayan bireyler, dikkatlerini olumsuz bilişsel ve duygusal durumlardan daha kolay uzaklaştırabilirler. Bunun yanında, değerlendirme ve başa çıkma esnekliğine sahip bireyler, stresli durumları yeniden değerlendirerek olumsuz düşünce ve duygularını yönetebilme ve alternatif başa çıkma stratejileri oluşturma becerisi gösterirler. Arıc1Özcan, Çekici ve Arslan (2019) tarafından üniversite öğrencileri üzerinde yürütülen bir araştırmada, psikolojik dayanıklılık ve stres toleransı arasında bilişsel esnekliğin aracılığının anlamlı olduğu gösterilmiştir. Psikolojik dayanıklılığa sahip bireylerin stresli durumlara nasıl başarılı bir şekilde uyum sağladığının anahtar faktörlerinden birisi bilişsel esnekliktir. Psikolojik dayanıklılık, çevrenin değişen taleplerini karşılamak için sosyal, bilişsel ve duygusal kaynakların esnek kullanımı olarak tanımlanmaktadır (Block ve Block, 1980; Block ve Kremen, 1996). Bu tanıma göre, psikolojik dayanıklılı̆̆ının yapısı değişime uyum sağlamada esnekliği içermektedir ve ikisi arasında karşılıklı bir ilişki söz konusudur. Bilişsel esneklik affedicikle de yakından ilişkilidir. Örneğin, Heartland Affetme Ölçeği'nin geliştirilmesi çalışmasında (Thomson vd., 2005) bilişsel esneklik ve affedicilik arasında anlamlı düzeyde ilişkili olduğu bulunmuştur. Bilişsel esneklik azaldıkça, bireyler olumsuz değerlendirilen deneyimleri kontrol etme veya bunlardan kaçınma ihtiyacı konusunda daha katı kurallar oluşturabilirler (Heyes 2004). Palm ve Follette, (2011), bilişsel esnekliğin azalmasının daha fazla deneyimsel kaçınmaya yol açtı̆̆ını belirtmişlerdir. Affedicilikte ise ihlali yapan kişiye karşı olumsuz duyguların 
azaltılması söz konusudur (McCullough, Pargament, ve Thoresen, 2000). Bireyin, ihlali yeniden çerçevelemek için gerekli bilişsel, duygusal ve/veya davranışsal çalışmaları yapması gerekmektedir (Thompson vd., 2005). Kuramsal açıklamalardan yola çıkarak (Gabrys vd., 2018; Thompson vd., 2005), bilişsel esneklik düzeyi düşük bireylerin olumsuz duyguları üzerinde kontrol sağlayamadıklarını ve affetmeyi gerektiren durumlarda başa çıkma esnekliği sergileyemedikleri söylenebilir.

Affetmedeki yaş farklılıklarına ilişkin önceki araştırma bulguları, gençlere oranla daha ileri yaş gruplarında affetme istekliliğinde ortalama bir artış olduğunu göstermektedir (Allemand, 2008). Kişiler arası çatışmalarla karşılaşıldığında yapıcı tepki verme kapasitesi yaşam boyu gelişmekte ve yaş alma ile ilişkilendirilmektedir (Bono ve McCullough 2004). İnsanlar yaş aldıkça, duygusal olarak yakın ilişkilerin sürdürülmesiyle giderek daha fazla ilgilenirler (Carstensen vd., 2006). Bu nedenle, olumsuz duygu deneyimlerini azaltan affetme gibi davranışlarda bulunma olasılığı yaşla birlikte artış göstermektedir.

Beliren yetişkinlik dönemi, yaşam boyu gelişim sürecinde kritik bir öneme sahiptir (Arnett, 2000). Pek çok üniversite öğrencisinin evinden ve ailesinden ayrıldığı, yeni insanlarla ve kültürlerle etkileşimde bulunmak zorunda olduğu, kendilerinden beklenen akademik görevlerin yanında, yeni kişilerarası ilişkileri sürdürmekle karşı karşıya kaldığı bu gelişim dönemi bazı öğrenciler için zor olabilmektedir (Arnett, 2000; Benn, Harvey, Gilbert, ve Irons, 2005). Yaşamın bu kritik evresinde, düşük düzeyde intikam ve kaçınma motivasyonlanı ve yüksek düzeyde affedicilik motivasyonu, olumsuz kişilerarası olaylara yanıt olarak olumlu ilişkileri kolaylaştıran avantajlı stratejileri yansıtabilir (Ghaemmaghami, Allemand ve Martin, 2011).

Yukarıdaki kuramsal açıklamalar ve araştırma bulguları ışığında bu araştırma, beliren yetişkinlik döneminde olan üniversite öğrencilerinde psikolojik dayanıklılık, bilişsel kontrol/esneklik ve affedicilik arasındaki ilişkileri incelemeyi amaçlamaktadır. Araştırmada psikolojik dayanıklılık düzeyi yüksek üniversite öğrencilerinin artan bilişsel kontrol/esneklik aracılığıyla daha yüksek affediciliğe sahip olacağı öngörülmüştür. Alan yazında psikolojik dayanıklılık ve affedicilik ilişkisini ele alan pek çok çalışma olsa da, bu çalışma bilişsel kontrol/esnekliğin iki faktörlü yapısının bu ilişkideki aracıllğı̆ı ortaya koyması bakımından ilk çalışma özelliği taşımaktadır. 


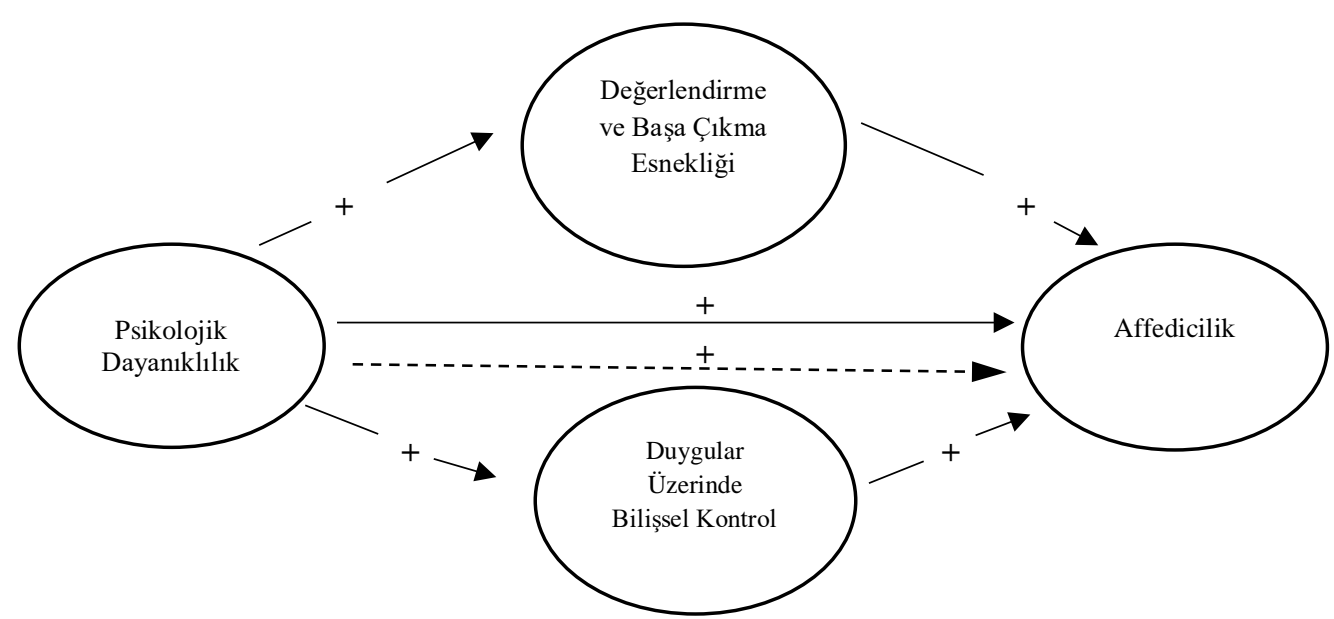

Yöntem

Şekil 1. Hipotez Modeli

\section{Araştırma Modeli}

Bu çalışma ilişkisel araştırma modeline dayalı olarak tasarlanmıştır. Çalışmada, psikolojik dayanıklılık, duygular üzerinde bilişsel kontrol, değerlendirme/başa çıkma esnekliği ve affedicilik değişkenleri arasındaki ilişkiler aracllık analizi ile incelenmiştir.

\section{Çalışma Grubu}

Araştırma, Türkiye'nin güneyinde, Akdeniz Bölgesi'nde yer alan bir devlet üniversitesinde eğitim alan 354 öğrenci üzerinde gerçekleştirilmiştir. Katılımclların 141'i (\%40) Eğitim Fakültesi'nin çeşitlibölümlerinde lisans eğitimi alan öğrencilerden, 213’ü (\% 60) pedagojik formasyon eğitimi alan öğrencilerden oluşmaktadır. Katılımcıların 142'si (\% 40.1) kadın, 184'ü (\% 52) erkektir. Geriye kalan 28 kişi (\%7.9) cinsiyetini belirtmemiştir. Katılımcıların yaş ortalamaları 22.79'dur (SS: 4.20). Araştırma grubunun belirlenmesinde, ulaşılabilir örneklem üzerinde çalışmayı kapsayan uygun örnekleme yöntemi (Cohen, Manion, ve Morrison, 2007) kullanılmıştır. 


\section{Veri Toplama Araçlan}

Ego-Dayanıklılık Ölçeği (EDÖ). Block ve Kremen (1996) tarafından geliştirilen ölçme aracı pozitif olarak ifade edilmiş 14 maddeden oluşmaktadır. Ölçeğin geliştirilmesi süreci 18-23 yaşları arasında 98 katılımcı üzerinde gerçekleştirilmiştir. Ölçme aracı için hesaplanan Cronbach alfa güvenirlik katsayısı .76 olarak bildirilmiştir. Ölçek 5 yıl sonra aynı katılımcılara tekrar uygulanmış ve düzeltilmemiş zayıflama (uncorrected attenuation) katsayısı kadınlar için .51, erkekler için .39 ve düzeltilmiş zayıflama (corrected attenuation) katsayısı kadınlar için .67 ve erkekler için .51 olarak hesaplanmıştır. Türkçe formunun psikometrik özelliklerinin değerlendirilmesinde açımlayıcı ve doğrulayıcı faktör analizleri yapılmış, ego dayanıklılığındaki varyansın \% 47'sini açıklayan 3 faktörlü modelin "toparlanmaya yönelik kişisel güçlü yönler", "kendine yönelik olumlu değerlendirmeler" ve "yeniliklere açı olma" ortaya çıtığı belirtilmiştir (Karaırmak, 2007). Ölçekten alınan puanlar 14 ile 56 arasında değişmektedir. Bu çalışmada ölçekten alınan toplam puan kullanılmıştır. Cronbach alfa katsayısı .80 olarak hesaplanmıştır.

Bilişsel Kontrol/Esneklik Ölçeği (BKEÖ). Gabrys vd. (2018) tarafından geliştirilen ölçme aracı, bireyin araya giren, istenmeyen (olumsuz) düşünce ve duygular üzerindeki kontrol sağlama becerisini ve stresli bir durumla esnek bir şekilde başa çıkma becerisini ölçmeyi amaçlamaktadır. “Değerlendirme ve Başa Çıkma Esnekliği" ve "Duygular Üzerinde Bilişsel Kontrol" olmak üzere iki faktörlü ölçme aracı her faktörde 9 maddeyi kapsayan 18 maddeden oluşmaktadır. BKEÖ'nün Türkçe formunun psikometrik özellikleri; dilsel eşdeğerlik, madde analizi, yapı geçerliği (yaklaşan geçerlik, diğer yapılarla ilişkiler, iç tutarlık) ve Cronbach Alfa güvenirlik sinama yöntemleriyle incelenmiştir (Demirtaş, 2019). DFA sonucu uyum indeksi değerleri $X^{2} / \mathrm{sd}=2.63$, RMSEA $=.08, \mathrm{CFI}=.96$, IFI $=.96$ olarak rapor edilmiştir. Bu çalışma için hesaplanan Cronbach alfa güvenirlik katsayıları "Değerlendirme ve Başa Çıkma Esnekliğii" için .89, "Duygular Üzerinde Bilişsel Kontrol” için .82, ölçeğin tümü için ise $.88^{\prime}$ dir. Bu çalışmada faktörlerden alınan toplam puanlar kullanılmıştır.

Heartland Affetme Ölçeği (HAÖ). Ölçme aracı Thompson vd. (2005) tarafından, bireyin affedici olmaya yönelik genel eğilimini (sürekli affedicilik) ölçme 
amacıyla geliştirilmiştir. 18 maddeden oluşan ölçek "Kendini Affetme", "Başkalarını Affetme" ve "Durumu Affetme" olmak üzere üç faktörden oluşmaktadır. Türkçe formunun psikometrik özelliklerinin değerlendirilmesinde doğrulayıcı faktör analizi gerçekleştirilmiş ve ölçeğin üç faktörlü yapısının uyum değerleri $\mathrm{X}^{2} / \mathrm{sd}=2.33$, $\mathrm{RMSEA}=.06$, GFI $=.96, \mathrm{CFI}=.90$ olarak rapor edilmiştir (Bugay ve Demir, 2010). Ölçeğin Cronbach alfa güvenirlik katsayıları "Kendini Affetme" için .64, "Başkalarını Affetme" için .79, "Durumu Affetme" için .76, tümü için .81 olarak hesaplanmıştır. Bu çalışma için hesaplanan Cronbach güvenirlik katsayıları sırasıyla $.55, .72$, .69 ve .80 'dir. Bu çalışmada ölçekten alınan toplam puan kullanılmıştır.

\section{İşlem ve Veri Analizi}

Araştırmanın verileri 2018-2019 Eğitim Öğretim yılında toplanmıştır. Veri toplama araçları araştırmacı tarafından sınıf ortamında uygulanmıştır. Araştırmada bilgilendirilmiş onam sunularak, gönüllü̈lük esas alınmıştır. Verilerin analizinde betimsel istatistikler, Pearson korelasyon katsayısı kullanılmıştır. Verilerin "doğrusallık" ve "normallik" sayıltılarına zarar verecek uç değerler olup olmadığını anlamak amacıyla Mahalanobis uzaklık değerleri hesaplanmış, analizleri olumsuz yönde etkileyecek uç değerlere rastlanmamıştır. Verilerin normalliğini belirlemek amacıyla basıklık ve çarpıklık değerleri incelenmiştir. Basıklık ve çarpıklık değerleri, verilerin normal dağılımdan önemli bir sapma göstermediğini ortaya koymuştur (Tablo 1). Değişkenler arası ilişkiler incelendiğinde korelasyon değerlerinin .34 ile .53 arasında değiştiği böylece çoklu bağlantı problemi olmadığı görülmüştür. Araştırmada, test edilen modelin aracilık etkilerinin istatistiksel olarak anlamlılığı, Sıradan En Küçük Kareler Regresyona dayalı yaklaşım ve Bootstrap Yöntemi ile incelenmiştir (Hayes, 2012; 2017; Preacher ve Hayes, 2008). Araştırmanın Bootstrap analizleri, PROCESS Macro aracilığıyla "Multiple Mediation Model 4" yürütülerek gerçekleştirilmiştir. Araştırmada anlamlılık düzeyi .05 olarak alınmıştır. Verilerinin analizinde, IBM SPSS 22.0 programı kullanılmıştır. 


\section{Bulgular}

\section{Betimleyici İstatistikler ve Korelasyon Analizi}

Araştırmada yer alan değişkenlere yönelik betimsel istatistikler ve korelasyon değerleri Tablo 1'de sunulmuştur.

Tablo 1. Araştırmanın Değişkenlerine İlişkin Betimsel İstatistikler ve Pearson Korelasyon Katsayısı Değerleri

\begin{tabular}{lllll}
\hline Değişken & $\mathbf{1}$ & $\mathbf{2}$ & $\mathbf{3}$ & $\mathbf{4}$ \\
\hline $\begin{array}{l}\text { 1. Psikolojik Dayanıklılık } \\
\text { 2. Değerlendirme ve }\end{array}$ & - & & & \\
$\quad$ Başa Çıkma Esnekliği & $.49^{* * *}$ & - & & \\
$\begin{array}{l}\text { 3. Duygular Üzerinde } \\
\text { Bilişsel Kontrol }\end{array}$ & & & & \\
4. Affedicilik & $.38^{* * *}$ & $.50^{* *}$ & - & \\
\hline Ortalama & $.34^{* *}$ & $.38^{* *}$ & $.53^{* *}$ & - \\
Standard Sapma & 42.91 & 47.91 & 35.53 & 77.23 \\
Çarpıklık & 6.40 & 8.63 & 9.86 & 14.96 \\
$\quad$ Basıklık & -.25 & -.38 & .33 & .09 \\
\hline
\end{tabular}

Not. $N=354^{* *} p<0.01$

Tablo 1'deki değerler incelendiğinde, psikolojik dayanıklılık ile değerlendirme ve başa çıma esnekliği $(r=.49, p<0.01)$, duygular üzerinde bilişsel kontrol $(r=.38, p<0.01)$ ve affedicilik $(r=.34, p<0.01)$ arasında pozitif yönde anlamlı ilişkiler olduğu görülmektedir. Ayrıca değerlendirme ve başa çıma esnekliği ile duygular üzerinde bilişsel kontrol $(r=.50, p<0.01)$ ve affedicilik $(r=.38, p<0.01)$ arasında pozitif yönde ilişkiler vardır. Son olarak duygular üzerinde bilişsel kontrol ve affedicilik $(r=.53, p<0.01)$ değişkenleri pozitif yönde ilişkilidir. 


\section{Aracılık Analizi}

Psikolojik dayanıklılık ile affedicilik arasındaki ilişkide değerlendirme ve başa çıkma esnekliği ile duygular üzerinde bilişsel kontrol değişkenlerinin paralel çoklu aracilığının test edildiği modele ilişkin bulgular Şekil 1'de sunulmuştur.

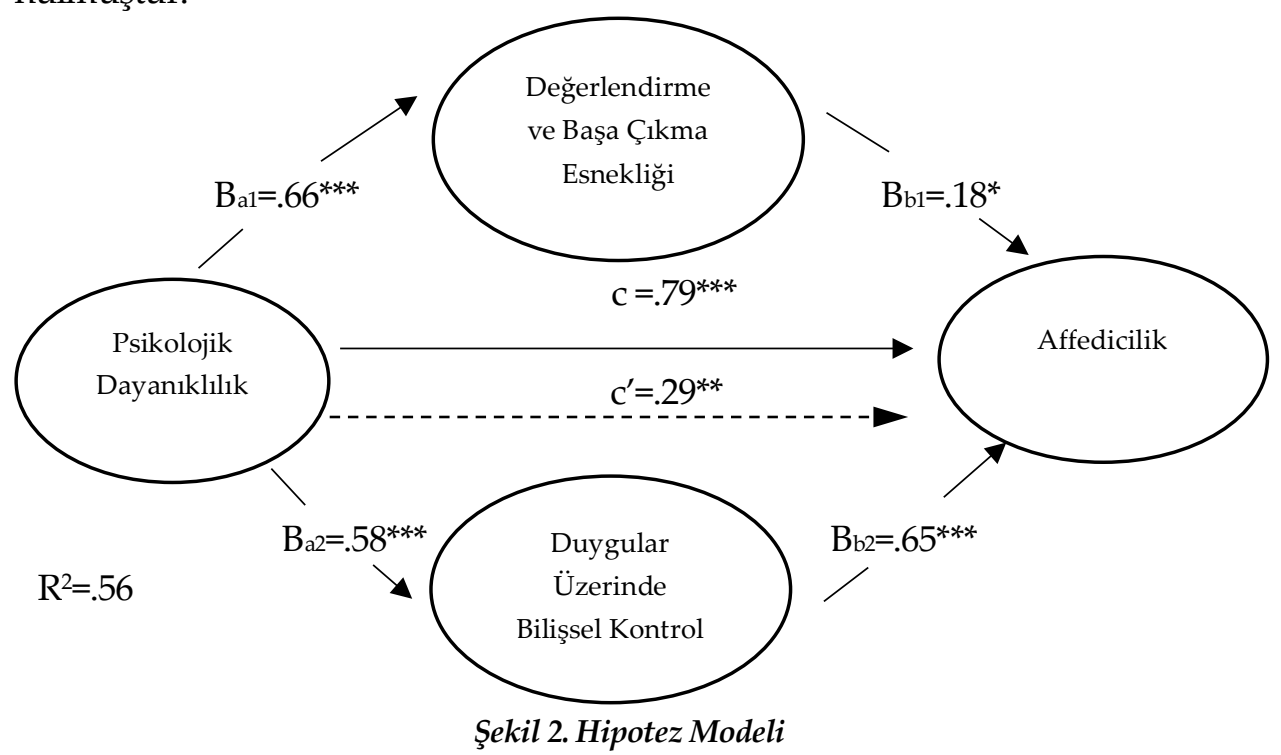

Şekil 2'deki değerler incelendiğinde, psikolojik dayanıklılığın affedicilik üzerindeki toplam etkisi ( $c=.79, \mathrm{SH}=.11, t=6.73, p<.001)$ anlamlıdır. Ayrıca psikolojik dayanıklılığın, değerlendirme ve başa çıkma esnekliği $(\mathrm{Ba1}=.66, \mathrm{SH}$ $=.06, t=10.54, p<.001)$ ile duygular üzerinde bilişsel kontrol $\left(\mathrm{B}_{\mathrm{a} 2}=.58, \mathrm{SH}=\right.$ $.07, t=7.58, p<.001$ ) üzerindeki doğrudan etkisi anlamlıdır. Bunun yanında, değerlendirme ve başa çıkma esnekliğinin $(\mathrm{Bb1}=.18, \mathrm{SH}=.09, t=1.92, p<.05)$ ve duygular üzerinde bilişsel kontrolün ( $\mathrm{Bb2}=.65, \mathrm{SH}=.07, t=8.26, p<.001$ ) affedicilik üzerindeki doğrudan etkisi anlamlıdır. Psikolojik dayanıklılık, değerlendirme/başa çlkma esnekliği ve duygular üzerinde bilişsel kontrol eş zamanlı olarak modele alındığında doğrudan etki açısından psikolojik dayanıklılık ile affedicilik arasındaki ilişki azalmış ancak anlamlılık değeri aynı düzeyde kalmaya devam etmiştir ( $\left.c^{\prime}=.29, \mathrm{SH}=.12, t=2.41, p<.01\right)$. Tüm model istatistiksel olarak anlamlıdır $(\mathrm{F}(3-350)=52.25, p<.001)$ ve affedicilikteki toplam 
varyansın \%56'sını açıklamaktadır. Araştırmada test edilen modelin değişkenleri arasındaki etkilere ilişkin değerler, Tablo 2' de sunulmuştur.

Tablo 2. Psikolojik Dayanıklılı̆̆ın, Değerlendirme/Başa Çıkma Esnekliği ve Duygular Üzerinde Bilişsel Kontrol Aracılıyla Affedicilik Üzerindeki Dolaylı Etkileri

\begin{tabular}{lllll}
\hline & \multicolumn{5}{c}{ Bootstrapping 95\% BCa } \\
Güven Aralığı \\
\hline Etkiler & Nokta Tahmini & SE & Düşük & Yüksek \\
Toplam Dolaylı Etkiler & .4972 & .0974 & .3159 & .6981 \\
Değerlendirme/Başa Çıkma Esnekliği & .1218 & .0599 & .0064 & .2426 \\
Duygular Üzerinde Bilişsel Kontrol & .3754 & .0812 & .2284 & .5502 \\
\hline Karşılaştırmalar & & & & \\
C1 & -.2536 & .0042 & -.4717 & -.0613 \\
\hline
\end{tabular}

$\mathrm{N}=354, \mathrm{k}=10000,{ }^{*} p<.05,{ }^{* *} p<.01,{ }^{* * *} p<.001$, BCa: Yanlılık hatasından arındırılmış ve düzeltilmiş (bias corrected and accelerated) 10000 bootstrap örneklemi. C1 = Değerlendirme/Başa Çıkma Esnekliği-Duygular Üzerinde Bilişsel Kontrol

Araştırmada test edilen modeldeki dolaylı etkinin istatistiksel açıdan anlamlılı̆̆ 10000 bootstrap örneklemi üzerinde incelenmiştir. Tahminler \% 95 güven aralığında değerlendirilmiş, yanlılık hatasından arındırılmış ve düzeltilmiş sonuçlar Tablo 2'de sunulmuştur. Bulgular, psikolojik dayanıklılığın , değerlendirme/başa çıkma esnekliği ve duygular üzerinde bilişsel kontrol aracilığıyla affedicilik üzerindeki toplam dolaylı etkisinin (toplam ve doğrudan etki / c-c' arasındaki fark) istatistiksel olarak anlamlı olduğunu göstermektedir (nokta tahmini $=.4972$ ve \% 95 BCa CI [.3159-.6981]. Modeldeki arac1 değişkenlere ilişkin etkiler incelendiğinde değerlendirme/başa çıkma esnekliğinin (nokta tahmini $=.1218$ ve \% 95 BCa CI [.0064-.2426] ve duygular üzerinde bilişsel kontrolün (nokta tahmini $=.3754$ ve \% 95 BCa CI [.2284-.5502] affedicilik üzerindeki toplam dolaylı etkisi istatistiksel olarak anlamlıdır. Ayrıca aracı değişkenlerden hangisinin daha güçlü etkiye sahip olduğuna ilişkin karşılaştırma istatistiksel olarak anlamlı bulunmuştur (nokta tahmini $=-.2536$ ve \% 95 BCa CI [-.4717-.0613]. Bu bulguya göre duygular üzerinde bilişsel kontrol daha güçlü etkiye sahiptir (nokta tahmini $=.3754$ ).

\section{Tartışma ve Sonuç}

Çalışmanın bulguları tüm değişkenlerin pozitif yönde korelasyon gösterdiğini ve bilişsel esnekliğin duygular üzerinde bilişsel kontrol ile değerlendirme ve başa çıkma esnekliği faktörlerinin psikolojik dayanıklılık ve affedi- 
cilik arasındaki ilişkiye aracılık ettiğini ortaya koymuştur. Ayrıca, araştırmada önerilen model istatistiksel olarak anlamlıdır ve affedicilikteki toplam varyansın \% 56'sını açılamaktadır.

Çalışmanın bulguları, psikolojik dayanıklılık ve affedicilik arasında pozitif yönde anlamlı ilişkiler olduğunu göstermiştir. Bu bulgu önceki araştırma sonuçlarını desteklemektedir. Örneğin, Halilova vd. (2020) tarafından yürütülen yakın tarihli bir çalışmada kişilik özelliği olarak psikolojik dayanıklılık ile affedici ve affedici olmayan tepkiler arasındaki ilişkileri hem yetişkinler hem de beliren yetişkinler üzerinde incelenmiştir. Araştırmacılar, psikolojik dayanıklılığı düşük olan bireylerin daha az affedici, psikolojik dayanıklılığ yüksek bireylerin daha fazla affedici olduğu sonucuna varmışlardır. Psikolojik dayanıklılığı yüksek bireyler, psikolojik baskılara bağlı olarak geçici, uyum gerektiren stres yaratan etki artık akut bir şekilde mevcut olmadığında, karakteristik ego kontrol düzeyine geri dönme becerisine sahiptir (Block, 1982). Psikolojik dayanıklılığın affediciliği yordayıcılığına yönelik çalışmalar, ortamdaki stres faktörlerini düzenleme becerisinin erdemli özellikleri ve bu özelliklerle ilgili uyumlu davranışların gelişimini kolaylaştırabileceğini göstermektedir (Dwiwardani vd., 2014). Sonuç olarak psikolojik dayanıklılığ yüksek bireylerin, kendilerini değişen koşullara uyarlama özellikleri ile affetmeye yönelik daha yüksek motivasyona sahip olduğu söylenebilir.

Araştırmada ortaya çıkan diğer sonuç psikolojik dayanıklılık ile bilişsel kontrol/esneklik arasında pozitif yönde anlamlı ilişkiler bulunmasıdır. Block ve Kremen'e göre (1996) psikolojik dayanıklılık, bir bireyin genelleştirilmiş, karakteristik bir niteliğini ifade eder ve basitçe oldukça spesifik, tek seferlik bir davranışa uygulanmaz. Bu tanım doğrultusunda ve araştırma sonucu ışığında psikolojik dayanıklılığa sahip bireylerin olumsuz duyguları üzerinde bilişsel kontrol ve stresli durumlarda başa çıkma esnekliğe sahip olduğu söylenebilir. Psikolojik dayanıklılığa sahip bireyler, olumsuz duyguların düzenlenmesinde olumlu duyguların faydalarının farkına varabilirler. Stresli zamanlarda yaşanan olumlu duygu deneyimleri, bireyleri yeni ve yaratıcı düşünceleri ve eylemleri izleme konusunda harekete geçirir. Böylece, keşif ve deneyimleme yoluyla, zamanla olumsuz duygusal yaşam deneyimlerine karşı psikolojik ve fizyolojik olarak yardımcı olan etkili başa çıkma kaynakları oluşturabilirler (Tugade ve Fredrickson, 2004).

Alan yazınla tutarlı olarak bilişsel esnekliğin alt boyutları ile affedicilik arasında pozitif yönde anlamlı ilişkiler bulunmuştur. Örneğin, Katovsich 
(2007) tarafından üniversite öğrencileri üzerinde yürütülen ilişkisel bir çalışmada bilişsel esnekliğin içsel ve kişilerarası boyutları ile affedicilik arasındaki ilişkiler incelenmiş ve beklendiği gibi pozitif yönde anlamlı ilişkiler bulunmuştur. Bilişsel kontrol bireyin, olumsuz düşünce ve duygularını kontrol edebilme becerisini; değerlendirme/başa çıkma esnekliği ise olumsuz düşünce/duyguları yönetme ve uygun tepkiyi seçmeden önce birden fazla alternatif başa çıkma stratejisi oluşturma eğilimini gösterir. Araştırmanin bulguları, hem bilişsel kontrolün hem de değerlendirme/başa çıkma esnekliğinin affedicilik üzerinde önemli rolü olduğunu ortaya koymaktadır.

Çalışmada önerilen hipotez modelin anlamlı düzeyde olduğu ve affedicilikteki varyansın \%56’sını açıkladığı ortaya çıkmıştır. Buna göre psikolojik dayanıklılık ile affedicilik arasındaki ilişkide bilişsel kontrol ve esnekliğin paralel çoklu aracılığı istatistiksel olarak anlamlıdır. Alan yazında psikolojik dayanıklılık ile affedicilik arasındaki ilişkiye yönelik pek çok çalışma olsa da aralarındaki ilişkiyi bilişsel esneklik açısından değerlendiren bir çalışmaya rastlanmamıştır. Psikolojik dayanıklılığa sahip bireylerin davranışlarıyla ilgili olumlu geribildirim alma, daha istikrarlı kişilik kalıpları gösterme ve böylece daha iyi bir kişilik-çevre uyumu elde etme olasılıkları daha yüksektir (Asendorpf ve Van Aken, 1991). Ayrıca psikolojik dayanıklılık, bilişsel alanların yanı sıra sosyal ve kişisel alanları da içerecek şekilde tanımlanan problem çözme stratejilerinin esnek bir şekilde yürütülmesi ile ilişkilidir (Block ve Block, 1980). İlgili alan yazın (Block ve Block, 1980; Gabrys vd., 2019) ve bu araştırmada test edilen modele ilişkin bulgular ışığında, psikolojik dayanıklılığa sahip bireylerin olumsuz duygu ve düşüncelerini kontrol edebilme, bunları yönetebilme ve alternatif başa çıkma stratejileri oluşturabilme becerisine sahip olduğu, ve bu özellikleri sayesinde daha fazla affedici oldukları söylenebilir.

Beliren yetişkinlik döneminde psikolojik dayanılılık ile affedicilik arasında bilişsel kontrol/esnekliğin aracılık rolünü inceleyen bu araştırma bazı sınırlılıklara sahiptir. Araştırmada katılımcıların uygun örnekleme yöntemiyle seçilmiş olması araştırmanın bir sınırlılığıdır. Bu bakımdan farklı örneklemler üzerinde yapılan benzer araştırmalar, araştırma bulgularının genellenebilirliğini arttırabilir. Araştırmanın diğer bir sınırlılığı, ilişkiler arasındaki nedenselliği ortaya koyamadığı için araştırmanın kesitsel desende gerçekleşmesidir. Bu bakımdan değişkenler arasındaki ilişkilerin neden-sonuç bağlamında incelenmesi için deneysel çalışmalar yapılması önerilebilir. 
Bu sınırlılıklara rağmen, araştırmanın beliren yetişkinlik döneminde psikolojik dayanıklılık, bilişsel kontrol/esneklik ve affedicilik arasındaki ilişkilerin anlaşılmasına katkı sağlayacağı düşünülmektedir. Bu sonuçlardan yola çıkarak gelecek araştırmalar için bazı öneriler sunulabilir. Bu araştırmada test edilen modelden yola çıkarak bilişsel kontrol/esneklik ile diğer pozitif kişilik özellikleri arasındaki ilişkileri ele alan farklı modeller geliştirilebilir. Kesitsel araştırmaların yanında, karmaşık nedensel ilişkileri ortaya koyabilmek amacıyla deneysel ve boylamsal çalışmalar yapılması alana önemli katkı sağlayacaktır. Ayrıca, bu çalışmadan elde edilen bulgular doğrultusunda araştırmacılara, psikolojik danışma ve rehberlik programlarının önleyici ve geliştirici işlevine yönelik psiko-eğitim programları geliştirmeleri önerilebilir. Bu bağlamda, psikolojik dayanıklılığı geliştirmeyi amaçlayan programların bireylerin bilişsel kontrol/esneklik becerilerine ve dolayısıyla affedicilik düzeylerine katkı sağlayacağı düşünülmektedir. 


\title{
EXTENDED ABSTRACT
}

\section{Ego-Resiliency and Forgiveness in Emerging Adults: The Parallel Multiple Mediation of Cognitive Control/Flexibility}

\author{
Ayşe Sibel Demirtaş \\ Alanya Alaaddin Keykubat University
}

Positive psychology emphasizes the increased well-being and adaptation resulting from the resolution of interpersonal situations through positive interpersonal relationships and internal reflection (Lopez, Snyder, and Rasmussen, 2002). In line with this view, it is stated that forgiveness is psychologically beneficial for both the victim and the transgressor by affecting the physical, mental and social health (Worthington, Berry, and Parrott, 2001).

The concept of forgiveness discussed in this study is based on the approach of Thompson et al. (2005). According to this view, forgiveness is defined as "the framing of a perceived transgression such that one's responses to the transgressor, transgression, and sequelae of the transgression are transformed from negative to neutral or positive." (p. 318).

The important structure closely related to forgiveness is ego-resiliency. Block and Cremen (1996) defined ego-resiliency as "the ability to adapt one's level of emotional control up or down appropriate to the circumstances presented". The literature provides important evidence for the relationship between ego-resiliency and forgiveness (Anderson, 2006; Divvyalakshmi and Indumathy, 2018).

Another important characteristic associated with ego-resiliency is cognitive flexibility. According to Gabrys, Tabri, Anisman, and Matheson (2018), cognitive flexibility is a structure consisting of two factors: "cognitive control over emotion" and "appraisal and coping flexibility". Cognitive control over emotion defines the ability of the individual to control negative thoughts and emotions that appear suddenly and repetitively in a stressful situation. Appraisal/coping flexibility refers to the individual's ability to engage in a series of effortful behaviors that can facilitate the detailed and appropriate assessment of a stressful situation as well as the selection of various coping strategies. In the study of the development of the Heartland Forgiveness Scale 
(Thomson et al., 2005), it was shown that there was a significant relationship between cognitive flexibility and forgiveness.

In light of the above theoretical explanations and research findings, this study aims to examine the relationships among ego-resiliency, cognitive control/flexibility, and forgiveness in emerging adulthood. Although there are many studies that address the relationship between resilience and forgiveness in the literature, this study is the first in terms of revealing the mediation of the two-factor structure of cognitive control/flexibility in the relationship between ego-resiliency and forgiveness.

A total of 354 undergraduates, $40.1 \%$ females (142) and 52\% males (184) (mean age 22.79) took part in the study. The remaining 28 people $(7.9 \%)$ did not state their gender. A convenience sample of undergraduates from a state university in south of Turkey was used. 141 of the participants (40\%) are students who have undergraduate education in various departments of the Faculty of Education, $213(60 \%)$ are students who have received pedagogical formation education. To collect data Turkish forms of Ego-Resiliency Scale (Block and Kremen, 1996), Cognitive Control and Flexibility Questionnaire (Gabrys et. al. 2018) and Heartland Forgiveness Scale (Thompson et. al., 2005) were used.

Descriptive statistics, Pearson's correlation method, an approach based on Ordinary Least Squares Regression, and Bootstrapping were used in the analyses of the data. Mahalanobis distance values were calculated in order to determine outliers and no outliers were found to exceed the chi-square critical value. As the values of skewness and kurtosis showed acceptable ranges in the region of -1 to +1 it was concluded that the scores did not show a significant deviation from the normal distribution (Tabachnick and Fidell, 2013). A multiple mediation model which involves "simultaneous mediation by multiple variables" (Preacher and Hayes, 2008, p. 880), was also used in the present study. The Bootstrapping analysis of the study was conducted by "Multiple Mediation Model 4" through PROCESS Macro 3 using IBM SPSS 24.0 (Hayes, 2017). A P-value of .05 was considered on the borderline of statistical significance.

Study findings showed that all variables were correlated positively and the parallel mediating roles of cognitive control over emotions and apprai$\mathrm{sal} /$ coping flexibility were statistically significant in the model. The mediational hypothetical model explained approximately $56 \%$ of the variance in 
ego-resiliency. According to the findings of model contrasts, cognitive control over emotions was greater than appraisal/coping flexibility in terms of the mediation power.

Ego-resiliency is associated with the flexible execution of problem solving strategies, which are defined to include social and personal areas as well as cognitive areas (Block and Block, 1980). In the light of the related literature (Block and Block, 1980; Gabrys et al., 2019) and the findings of the model tested in this study, individuals with ego-resiliency have the ability to control and manage their negative emotions and thoughts and to create alternative coping strategies, and it can be concluded that because of their ego-resiliency and cognitive flexibility they may be more forgiving.

This study, which examines the mediating role of cognitive control/flexibility between ego-resiliency and forgiveness in emerging adulthood, has some limitations. It is a limitation of the study that the participants were selected with the convenience sampling method. In this respect, similar studies on different study groups may increase the generalizability of the research findings. Another limitation of the research is that the study was carried out in a cross-sectional design since it cannot reveal the causality between the relationships. In this regard, it may be suggested to conduct experimental studies to examine the relationships between variables in the context of cause and effect.

\section{Kaynakça / References}

Allemand, M. (2008). Age differences in forgivingness: The role of future time perspective. Journal of Research in Personality, 42, 1137-1147. doi: 10.1016/j.jp.2008.02.009

Anderson, M. A. (2006). The relationship among resilience, forgiveness, and anger expression in adolescents. Electronic Theses and Dissertations. 416. 15 Temmuz 2020

tarihinde https://digitalcommons.library.umaine.edu/etd/416 adresinden erişildi.

Asendorpf, J. B., ve Van Aken, M. A. (1991). Correlates of the temporal consistency of personality patterns in childhood. Journal of Personality, 59(4), 689-703. doi: 10.1111/j.1467-6494.1991.tb00927.x

Arıc1-Özcan, N., Çekici, F. ve Arslan, R. (2019). The relationship between resilience and distress tolerance in college students: The mediator role of cognitive flexibility and difficulties in emotion regulation. International Journal of Educational Methodology, 5(4), 525-533. 
Arnett, J. J. (2000). Emerging adulthood: A theory of development from the late teens through the twenties. American Psychologist, 469-480.

Benn, I., Harvey, J. E., Gilbert, P. ve Irons, C. (2005). Social rank, interper-sonal trust and recall of parental rearing in relation to homesickness. Personal Individual Difference, 38, 1813-1822.

Berry, J. W., Worthington, E. L., Jr., Parrott, L. III, O'Connor, L. E. ve Wade, N. G. (2001). Dispositional forgivingness: Development and construct validity of the Transgression Narrative Test of Forgivingness (TNTF). Personality and Social Psychology Bulletin, 27(10), 1277-1290. doi: 10.1177/01461672012710004

Block, J. (1982). Assimilation, accommodation, and the dynamics of personality development. Child Development, 53, 281-295.

Block, J. H. ve Block, J. (1980). The role of ego-control and ego-resiliency in the organization of behavior. W. A. Collins (Ed.), Development of cognition, affect and social relations: The Minnesota symposia on child psychology içinde (ss. 39-101). Hillsdale, NJ: Erlbaum.

Block, J. (2002). Personality as an affect-processing system. Mahwah, NJ: Erlbaum

Block, J., ve Kremen, A. M. (1996). IQ and ego-resiliency: Conceptual and empirical connections and separateness. Journal of Personality and Social Psychology, 70, 349361.

Bono, G., ve McCullough, M. E. (2004). Religion, forgiveness, and adjustment in older adults. In K. W. Schaie, N. Krause, ve A. Booth (Eds.), Religious influences on health and well-being in the elderly içinde (s. 163-186). New York: Springer

Bono, G.,McCullough, M. E. ve Root, L. M. (2008). Forgiveness, feeling connected to others, and well-being: Two longitudinal studies. Personality and Social Psychology Bulletin, 34, 182-195.

Bugay, A. ve Demir, A. (2010a). A Turkish Version of Heartland Forgiveness Scale. Procedia Social and Behavioral Sciences, 5, 1927-1931.

Carstensen, L. L., Mikels, J. A., ve Mather, M. (2006). Aging and the intersection of cognition, motivation, and emotion. In J. E. Birren \&W. K. Schaire (Eds.), Handbook of the psychology of aging içinde (6. ed., s. 343-362). Amsterdam, The Netherlands: Elsevier

Cohen, L., Manion, L. ve Morrison, K. (2007). Research methods in education. London: Routledge.

Demirtas, A. S. (2019). Stresli durumlarda bilişsel kontrol ve bilişsel esneklik: Bir ölçek uyarlama çalışması. Psikoloji Calışmalan - Studies in Psychology, 39(2), 345-368. doi: 10.26650/SP2019-0028. 
Dennis, J. P., ve Vander Wal, J. S. V. (2010). The Cognitive Flexibility Inventory: Instrument development and estimates of reliability and validity. Cognitive Therapy and Research, 34(3), 241-253. doi: 10.1007/s10608-009-9276-4.

Dwiwardani, C., Hill, P. C., Bollinger, R. A., Marks, L. E., Steele, J. R., Doolin, H. N., ..., Davis, D. E. (2014). Virtues develop from a secure base: Attachment and resilience as predictors of humility, gratitude, and forgiveness. Journal of Psychology and Theology, 42(1), 83-90.

Divvyalakshmi, N. N ve Indumathy, J. (2018). Resilience, forgiveness and personal well-being among adults. International Journal of Recent Scientific Research, 9(2), 24437-24441. doi: 10.24327/ijrsr.2018.0902.1661.

Gabrys, R. L., Tabri, N., Anisman, H. ve Matheson, K. (2018). Cognitive control and flexibility in the context of stress and depressive symptoms: The Cognitive Control and Flexibility Questionnaire. Frontiers in Psychology, 9, 1-19. doi: 10.3389/fpsyg.2018.02219

Ghaemmaghami, P., Allemand, M., ve Martin, M. (2011). Forgiveness in younger, middle-aged and older adults: Age and gender matters. Journal of Adult Development, 18, 192-203. doi:10.1007/s10804-011-9127-x

Gurvis, J. ve Calarco, A. (2007). Adaptability: Responding effectively to change. USA: Center for Creative Leadership.

Halilova, J. G., Struthers, C. W., Guilfoyle, J. R., Shoikhedbrod, A., Van Monsjou, A. ve George. M. (2020). Does resilience help sustain relationships in the face of interpersonal transgressions? Personality and Individual Differences, 160, 109928.

Hayes, S. C. (2004). Acceptance and commitment therapy, relational frame theory, and the third wave of behavioral and cognitive therapies. Behavior Therapy, 35, 639665.

Hayes, A. F. (2012). Process: A versatile computational tool for observed variable mediation, moderation, and conditional process modeling. 18 https://www.processmacro.org/download.html adresinden erişildi.

Hayes, A. F. (2017). Introduction to mediation, moderation, and conditional process analysis: A regression-based approach. New York: Guilford Press.

Karaurmak, Ö. (2007). Investigation of personal qualities contributing to psyhological resilience among earthquake survivors: A model testing study (Yayımlanmamış doktora tezi). Orta Doğu Teknik Üniversitesi, Ankara.

Katovsich, R. B. (2007). Empathy and cognitive flexibility as correlates of forgiveness. Dissertations. 483. 21 Temmuz 2020 tarihinde https://digitalcommons.andrews.edu/dissertations/483 adresinden erişildi. 
Klohnen, E. C. (1996). Conceptual analysis and measurement of the construct of egoresiliency. Journal of Personality and Social Psychology, 70(5), 1067-1079. doi: 10.1037/0022-3514.70.5.1067.

Lopez, S. J., Snyder, C. R. ve Rasmussen, H. N. (2003). Striking a vital balance: Developing a complementary focus on human weakness and strength through positive psychological assessment. S. J. Lopez e C. R. Snyder (Ed.), Positive psychological assessment: A handbook of models and measures içinde (s. 3-20). American Psychological Association.

Mak, W. W. S., Ng, I. S. W. ve Wong, C. C. Y. (2011). Resilience: Enhancing well-being through the positive cognitive triad. Journal of Counseling Psychology, 58, 610617. doi: 10.1037/a0025195.

Martin, M. M. ve Rubin, R. B. (1995). Anew measure of cognitive flexibility. Psychological Reports, 76(2), 623-626.

McCullough, M. E., Pargament, K. I. ve Thoresen, C. E. (Eds.). (2000). Forgiveness: Theory, research, and practice. Guilford Press.

McCullough, M. E., Bellah, C. G., Kilpatrick, S. D. ve Johnson, J. L. (2001). Vengefulness: Relationships with forgiveness, rumination, well-being, and the Big Five. Personality and Social Psychology Bulletin, 27(5), 601-610. doi: $\underline{10.1177 / 0146167201275008}$

Palm, K. M., ve Follette, V. M. (2011). The roles of cognitive flexibility and experiential avoidance in explaining psychological distress in survivors of interpersonal victimization. Journal of Psychopathology and Behavioral Assessment, 33, 79-86. doi: 10.1007/s10862-010-9201-x

Philippe, F. L., Laventure, S., Beaulieu-Pelletier, G., Lecours, S. ve Lekes, N. (2011). Egoresiliency as a mediator between childhood trauma and psychological symptoms. Journal of Social and Clinical Psychology, 30(6), 583-598. doi: 10.1521/jscp.2011.30.6.583

Preacher, K. ve Hayes, A. (2008). Asymptotic and resampling strategies for assessing and comparing indirect effects in multiple mediator models. Behavior Research Methods, 40, 879-891. doi: 10.3758/BRM.40.3.879.

Seligman, M. E. (2002). Authentic happiness: Using the new positive psychology' to realize your potential for lasting fulfillment. New York: Free Press.

Thompson, L. Y., Snyder, C. R., Hoffman, L., Michael, S. T., Rasmussen, H. N. ve Billings, L. S. (2005). Dispositional forgiveness of self, others, and situations. Journal of Personality, 73,313-359. 
Tugade M. M. ve Fredrickson, B. L. (2004). Resilient individuals use positive emotions to bounce back from negative emotional experiences. Journal of Personality and Social Psychology, 86, 320-333.

Turnage, B., Hong, Y. J., Stevenson, A. P. ve Edwards, B. (2011). Social work students' perceptions of themselves and others: Self-esteem, empathy, and forgiveness. Journal of Social Service Research, 37(5), 1-11.

Worthington, E. L., Jr., Berry, J. W. ve Parrott, L. III. (2001). Unforgiveness, forgiveness, religion, and health. T. G. Plante ve A. C. Sherman (Ed.), Faith and health: Psychological perspectives içinde (s. 107-138). The Guilford Press.

Kaynakça Bilgisi / Citation Information

Demirtaş, A. S. (2021). Beliren yetişkinlikte psikolojik dayanıklılık ve affedicilik: Bilişsel kontrol/esnekliğin paralel çoklu aracıllğı. OPUSUluslararası Toplum Araştırmaları Dergisi, 17(35), 1968-1989. DOI: 10.26466/opus.790362 